\section{Nonminimum-Phase Phenomenon of PEM Fuel Cell Membrane Humidifiers}

\section{Dongmei Chen}

\author{
Huei Peng ${ }^{1}$ \\ Professor \\ e-mail: hpeng@umich.edu
}

Department of Mechanical Engineering, University of Michigan,

Ann Arbor, MI 48109-2125

A membrane-based humidifier that uses cooling water of a fuel cell system to humidify the inlet air is modeled and analyzed in this paper. This four-state lumped model is simple and yet captures the humidification behavior accurately. A peculiar characteristic of this system is the fact that it exhibits nonminimum-phase (NMP) behavior. The reason the NMP behavior exists and the effect of system parameters on the location of the NMP zero are analyzed. A proportional control algorithm is proposed to reject the effect of system disturbances, and a feed-forward algorithm is developed to ensure proper humidifier operation under air flow rate changes. Because the NMP zero exists in the disturbance-tooutput loop, the proposed algorithm was found to successfully eliminate the undershoot phenomena associated with the NMP zero. However, the disturbance-to-output loop is coupled with input-to-output loop, and the NMP zero could affect the feedback control design. [DOI: 10.1115/1.2936381]

\section{Introduction}

Polymer electrolyte membrane fuel cells (PEMFCs) have drawn much attention from industries and academia in recent years because they have high potential as a critical enabling technology for the inevitable migration toward a renewable energy society [1]. To operate efficiently and reliably, fuel cell membranes need to be properly hydrated. Water management has been recognized as a critical issue for PEMFCs' performance. In addition, PEMFCs for automotive applications operate in a dynamic environment, where the power required from the fuel cells is constantly changing because of the traffic conditions, vehicle auxiliary load, and drivers' decisions and activities. It is thus important to study stack humidity control during transient. The development of a dynamic fuel cell and humidifier model is an essential first step toward providing such solutions.

A thermodynamic model for a membrane humidifier using fuel cell cathode exhaust air as the vapor source was developed in Ref. [2]. This model captures the dynamics of gas flow, temperature, pressure, and relative humidity (RH). Humidifiers using cathode exhaust as the vapor source may have issues for packaging and thus are not as practical as those using cooling water. In this paper, the model developed in Ref. [2] is extended to describe a humidifier where water is used as the heat and vapor source to humidify the dry inlet gas. It is demonstrated that this humidifier exhibits nonminimum-phase (NMP) behavior, which results in undershoot in membrane vapor transfer rate under step changes in the inlet air

\footnotetext{
${ }^{1}$ Corresponding author.

Contributed by the Dynamic Systems, Measurement, and Control Division of ASME for publication in the Journal of Dynamic Systems, Measurement, and ConTROL. Manuscript received March 4, 2005; final manuscript received February 3, 2008; published online June 4, 2008. Review conducted by Suhada Jayasuriya.
}

flow. The effect of the humidifier parameters on the NMP zero location is analyzed. Subsequently, feedback and feed-forward control algorithms are developed to reject the effect of disturbances arising from the change of the inlet air flow rate, temperature, and $\mathrm{RH}$.

\section{Humidification System Modeling}

2.1 Humidifier. A thermodynamic model for a humidifier using the fuel cell exhaust gas to humidify the dry inlet gas was developed in Ref. [2]. In this paper, stack cooling water replaces the exhaust gas as the source to warm and humidify the dry inlet gas, which reduces the humidifier size and leads to a more compact design. The schematic diagram of a humidifier unit is shown in Fig. 1, where warm water diffuses from one side of the membrane to the other, with the gas and water flow in parallel to the membrane surface. The vapor transfer through the membrane is predominately determined by the water and gas flow rates (convective driving force), membrane pressure differential (diffusive driving force), membrane thickness, and fluid temperatures. There are three channels in each humidifier unit: a Channel A, which is the humidification channel, a Channel B, which is the heat transfer channel, and a Channel $\mathrm{C}$, which is the water channel where the fuel cell cooling water passes through. The dry inlet gas can be directed to go through either Channel A or Channel B. When the inlet gas passes through Channel $\mathrm{A}$, both heat and water vapor exchange with Channel $\mathrm{C}$ may occur. When the gas passes through Channel B, only heat exchange could happen. Depending on the position of the sliding plate, the gas will be directed to go through either Channel A to be humidified or Channel $\mathrm{B}$ to be heated only.

Based on the capacity of a fuel cell stack, the size and number of humidifier units can be determined. Assuming it is decided to have $N$ humidifier units, the number of units designated as Type A can be any number between 0 and $N$, depending on the desired $\mathrm{RH}$ of the exiting gas and stack current. For example, if the desired RH is $100 \%$, all the gas can be directed through A channels. Similarly, if the desired $\mathrm{RH}$ is $0 \%$, all the A channels will be closed. It should be noted that the authority of the humidifier in reducing humidity is limited. When the inlet air $\mathrm{RH}$ is positive, we will not get $0 \% \mathrm{RH}$ at the outlet even if no Channel A is used.

2.2 Control Volume Definition. Two control volumes are defined, as shown in Fig. 2. Control Volume 1 includes either Channel A or Channel B. Control Volume 2 includes Channel C. For Control Volume 1, the dry gas inlet mass rate, pressure, temperature, and RH are denoted as $r_{1, \text { in }}, P_{1, \text { in }}, T_{1, \text { in }}$, and $\Phi_{1, \text { in }}$, respectively. Those quantities for the outlet are denoted as $r_{1, \text { out }}, P_{1, \text { out }}$, $T_{1, \text { out }}$, and $\Phi_{1, \text { out }}$. If Control Volume 1 is Type $\mathrm{A}$, both vapor transfer $r_{v \text {,tr }}$ and heat transfer $Q r_{\mathrm{cv}}$ occur. If Control Volume 1 is Type B, only heat transfer occurs. For Control Volume 2, the water inlet mass flow rate, pressure, and temperature are denoted as $r_{w, \text { in }}, P_{w, \text { in }}$, and $T_{w, \text { in }}$, respectively. Moreover, those quantities for the outlet are denoted as $r_{w, \text { out }}, P_{w, \text { out }}$, and $T_{w, \text { out }}$. The model assumptions are the same as those in Ref. [2].

2.3 Humidifier Modeling. The equations to describe the humidifier are similar to those in Ref. [2], and are summarized below. Applying the first law of thermodynamics to Control Volume 1 , the energy equation is

$$
\begin{gathered}
\frac{d m_{g, 1}}{d t} u_{g, 1}+\frac{d m_{v, 1}}{d t} u_{v, 1}+m_{g, 1} u r_{g, 1}+m_{v, 1} u r_{v, 1}=Q r_{\mathrm{cv}}+r_{g, \text { in }} h_{g, \text { in }} \\
+r_{v, \text { in }} h_{v, \text { in }}+\frac{n}{N} r_{v, \text { tr }} h_{\text {mem }}-r_{g, \text { out }} h_{g, \text { out }}-r_{v, \text { out }} h_{v, \text { out }}
\end{gathered}
$$

where $d u_{k 1,1} / d t=C_{v_{k 1}} d T_{1, \text { out }} / d t, u r_{k 1,1}=C_{v_{k 1}} d T_{1, \text { out }} / d t, d h_{k 1, k 2} / d t$ $=C_{p_{k 1}} \dot{T}_{1, k 2}, d h_{v, \text { tr }} / d t=C_{p_{v}} \dot{T}_{\text {mem }}$, and $T_{\text {mem }}=T_{w, \text { in }}+T_{w, \text { out }} / 2$. The subscript $k 1$ is either $g$ (gas) or $v$ (vapor) in Control Volume 1, 


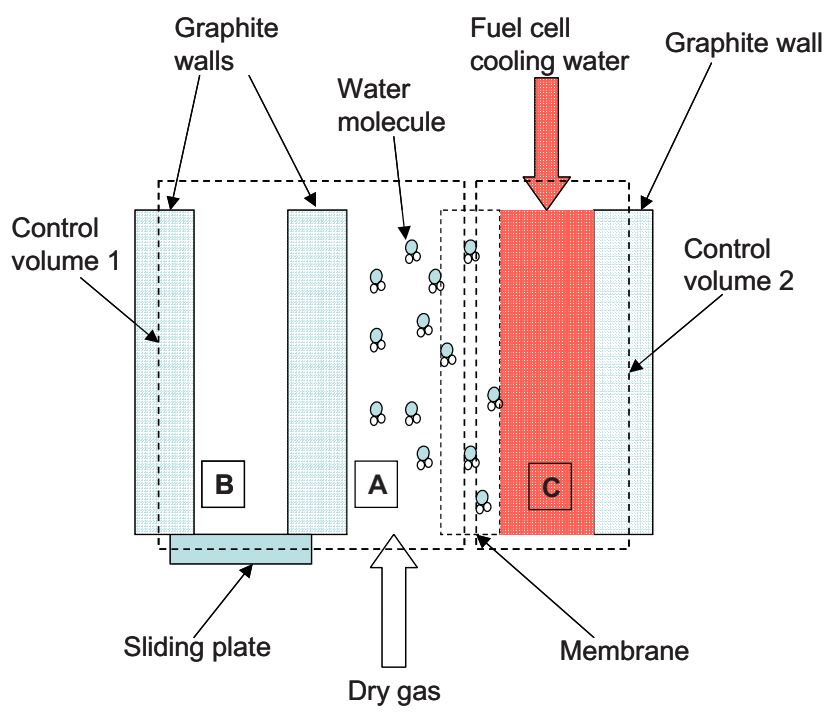

Fig. 1 One humidifier unit

and $k 2$ is either in (inlet) or out (outlet).

Applying the first law of thermodynamics to Control Volume 2, the energy equation is

$$
m_{w} C_{p_{w}} \frac{d T_{w, \text { out }}}{d t}=-Q r_{\mathrm{cv}}+r_{w, \text { in }} h_{w, \text { in }}-r_{w, \text { out }} h_{w, \text { out }}-\frac{n}{N} r_{v, \text { tr }} h_{\text {mem }}
$$

where $d h_{w, k 2} / d t=C_{p_{w}} \dot{T}_{w, k 2}$.

$d m_{g, 1} / d t$ and $d m_{v, 1} / d t$ are calculated from the mass continuity equations:

$$
\begin{gathered}
\frac{d m_{g, 1}}{d t}=r_{g, \text { in }}-r_{g, \text { out }} \\
\frac{d m_{v, 1}}{d t}=r_{v, \text { in }}+r_{v, \text { tr }}-r_{v, \text { out }} \\
r_{1, k 2}=r_{g, k 2}+r_{v, k 2} \\
\omega_{1, k 2}=\frac{G_{v}}{G_{g}} \frac{P_{v, k 2}}{P_{g, k 2}}
\end{gathered}
$$

$$
r_{g, k 2}=\frac{1}{1+\omega_{1, k 2}} r_{1, k 2}
$$

In addition, the outlet mass rate $r_{1, \text { out }}$ can be calculated from the nozzle equation:

$$
r_{1, \text { out }}=C_{r} \sqrt{P_{1, \text { out }}-P_{\mathrm{fc}, \text { in }}}
$$

where $p_{\mathrm{fc}, \text { in }}$ is the fuel cell inlet pressure. $C_{r}$ is the nozzle constant, which is typically obtained empirically. The water mass rate $r_{w}$ is calculated from

$$
r_{w}=r_{w, \text { in }}-r_{v, \text { tr }}-r_{w, \text { out }}
$$

The vapor transfer rate $r_{v, \text { tr }}$ between the two control volumes is calculated from $[3,4]$

$$
r_{v, \mathrm{tr}}=D_{w} \frac{C_{w}-C_{1}}{t_{m}} G_{v} A, \quad D_{w}=D_{\lambda} e^{\left(2416\left((1 / 303)-\left(1 / T_{\mathrm{mem}}\right)\right)\right)}
$$

where $C_{w}$ and $C_{1}$ are the water concentrations of the membrane on the water side and the air side, respectively, which are defined later in Eq. (12). The coefficient $D_{\lambda}$ is determined empirically and has a piecewise-linear form [3-5]

$$
D_{\lambda}= \begin{cases}10^{-6}, & \lambda_{\text {mem }}<2 \\ 10^{-6}\left(1+2\left(\lambda_{\text {mem }}-2\right)\right), & 2 \leq \lambda_{\text {mem }} \leq 3 \\ 10^{-6}\left(3-1.167\left(\lambda_{\text {mem }}-3\right)\right), & 3<\lambda_{\text {mem }}<4.5 \\ 1.25 \times 10^{-6}, & \lambda_{\text {mem }} \geq 4.5\end{cases}
$$

The water concentrations of the membrane on the water side and the gas side are

$$
C_{w}=\frac{\rho_{m, \mathrm{dry}}}{G_{m, \mathrm{dry}}} \lambda_{w} \quad C_{1}=\frac{\rho_{m, \mathrm{dry}}}{G_{m, \mathrm{dry}}} \lambda_{1}
$$

where the water content variables can be calculated from [3-5]

$$
\begin{aligned}
& \lambda_{1}=\left(0.043+17.81 \Phi_{1}-39.85 \Phi_{1}^{2}+36.0 \Phi_{1}^{3}\right) \\
& \lambda_{w}=14 \\
& \lambda_{\text {mem }}=\left(0.043+17.81 \frac{\Phi_{1}+1}{2}-39.85\left(\frac{\Phi_{1}+1}{2}\right)^{2}\right. \\
& \\
&\left.+36.0\left(\frac{\Phi_{1}+1}{2}\right)^{3}\right)
\end{aligned}
$$

The RH $\Phi_{1}=\Phi_{1, \text { out }}=P_{v, 1} / P_{\text {sat }, 1}, P_{\text {sat }, 1}$ is the saturation pressure of Control Volume 1 , which is determined by [3-5]

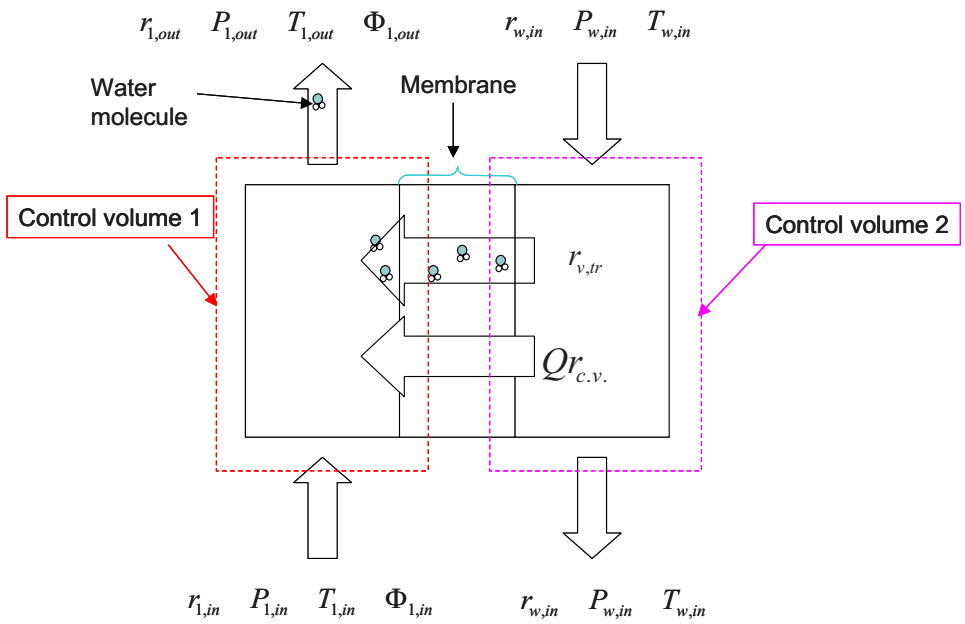

Fig. 2 Control volumes of one humidifier unit 
Table 1 Humidifier parameters
Membrane cross section area

Membrane dry density

Membrane dry equivalent weight

Number of humidifier unit

Channel hydraulic diameter

Air channel orifice restriction coefficient

Humidifier air Channel A volume

Humidifier air Channel B volume

Humidifier water Channel C volume
Membrane thickness
$280 \mathrm{~cm}^{2}$

$0.0025 \mathrm{~cm}$

$0.001 \mathrm{~kg} / \mathrm{cm}^{3}$

$1.0 \mathrm{~kg} / \mathrm{mol}$

381

$0.001 \mathrm{~m}$

0.0000022

$0.0145 \mathrm{~m}^{3}$

$0.0145 \mathrm{~m}^{3}$

$0.0145 \mathrm{~m}^{3}$

$$
\begin{aligned}
\log _{10}\left(P_{\text {sat }, 1}\right)= & -1.69 \times 10^{-10} T_{1}^{4}+3.85 \times 10^{-7} T_{1}^{3}-3.39 \times 10^{-4} T_{1}^{2} \\
& +0.143 T_{1}-20.92
\end{aligned}
$$

The vapor partial pressure of Control Volume $1, P_{v, 1}$, is computed from the ideal gas law.

$$
\begin{gathered}
P_{v, 1} V_{c 1}=R_{v} T_{1, \text { out }} m_{v, 1} \\
P_{g, 1} V_{c 1}=R_{g} T_{1, \text { out }} m_{g, 1} \\
P_{1, k 2}=P_{v, k 2}+P_{g, k 2}
\end{gathered}
$$

where $P_{g, 1}=P_{g, \text { out }}, P_{v, 1}=P_{v \text {,out }}$. The heat transfer rate between the two control volumes can be calculated from [6]

$$
Q r_{\mathrm{cv}}=U A \Delta T_{2 / 1}
$$

where $U$ is the overall heat transfer coefficient defined as

$$
U=\frac{1}{\left(1 / \bar{h}_{1}+1 / \bar{h}_{2}\right)}, \quad \bar{h}_{1}=\mathrm{Nu}_{D} \frac{k_{g}}{D_{h}}, \quad \bar{h}_{2}=\mathrm{Nu}_{D} \frac{k_{w}}{D_{h}}
$$

$\Delta T_{2 / 1}$ is the temperature difference between the water and the gas. For the counterflow arrangement,

$$
\Delta T_{2 / 1}=\frac{\left(T_{w, \text { in }}-T_{1, \text { out }}\right)-\left(T_{w, \text { out }}-T_{1, \text { in }}\right)}{\ln \left(\left(T_{w, \text { in }}-T_{1, \text { out }}\right) /\left(T_{w, \text { out }}-T_{1, \text { in }}\right)\right)}
$$

Based on the above equations, a four-state model is obtained that is summarized below.

The states are

$$
x=\left[\begin{array}{llll}
m_{g, 1} & m_{v, 1} & T_{1, \text { out }} & T_{w, \text { out }}
\end{array}\right]^{T}
$$
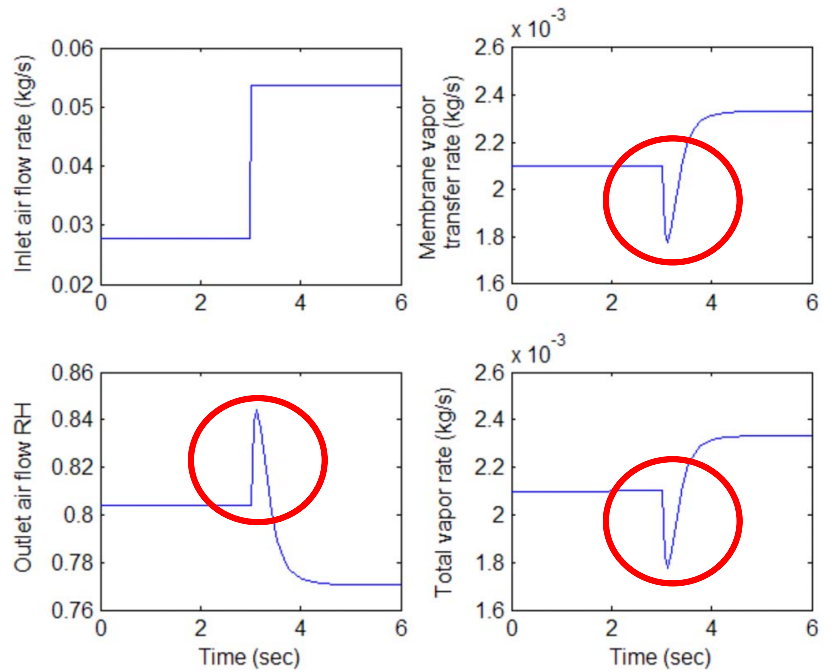

Fig. 3 System responses under a step increase of the inlet air flow rate (Inlet air temperature, $303^{\circ} \mathrm{K}$; inlet air $\mathrm{RH}, 0$; inlet water temperature, $353^{\circ} \mathrm{K}$ )
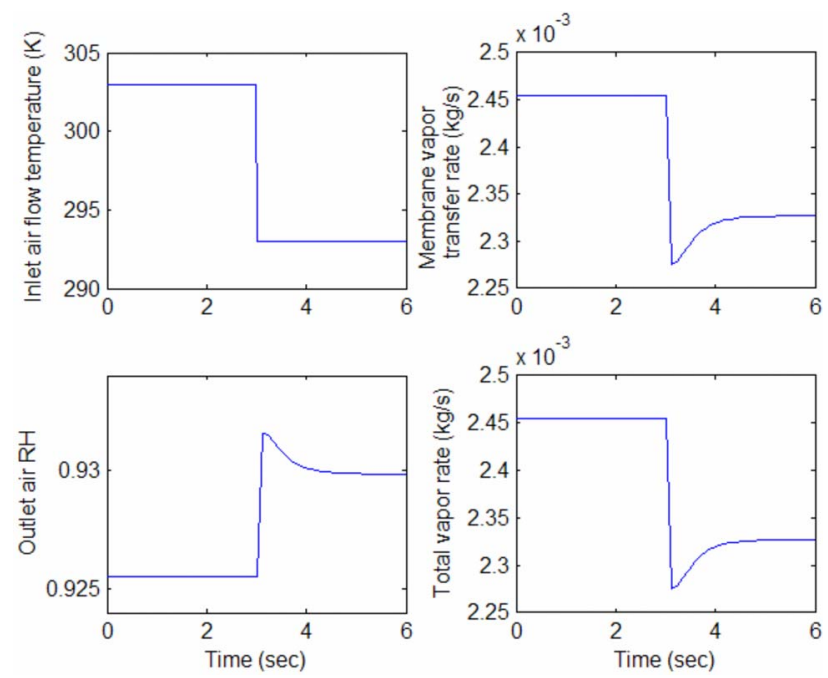

Fig. 4 System responses under a step decrease of the inlet air temperature (inlet air flow rate, $0.02785 \mathrm{~kg} / \mathrm{s}$; inlet air RH, 0; inlet water temperature, $353^{\circ} \mathrm{K}$ )

Possible measurements include

$$
y=\left[\begin{array}{llllll}
Q r_{\mathrm{cv}} & r_{v, \mathrm{tr}} & r_{1, \mathrm{out}} & P_{1, \mathrm{out}} & \Phi_{1, \mathrm{out}} & r_{w, \mathrm{out}}
\end{array}\right]^{T}
$$

The performance is

$$
z=\left\lfloor r_{v, \mathrm{tr}}\right\rfloor=f\left(m_{g, 1} \quad m_{v, 1} \quad T_{1, \text { out }} \quad T_{w, \text { out }}\right)
$$

The control input is

$$
u=\frac{1}{N}[n]
$$

The disturbances are

$$
w=\left[\begin{array}{lllllll}
r_{1, \text { in }} & T_{1, \text { in }} & P_{1, \text { in }} & \Phi_{1, \text { in }} & P_{w, \text { in }} & P_{w, \text { out }} & T_{w, \text { in }}
\end{array}\right]^{T}
$$

\section{Simulation Results, Discussion, and Experimental Validation}

3.1 Dynamic Simulations. The model presented in the previous section is implemented in the MATLAB/SIMULINK environment. We only study cathode humidification, i.e., the dry gas to be humidified is air. The system parameters are summarized in Table 1.

Among the disturbances to the humidifier system, the most important ones are the inlet air flow rate, temperature, and RH. The open-loop behaviors of the humidifier under the three disturbances are presented below. Figure 3 shows that when there is a step increase in the inlet air flow rate, the membrane vapor transfer rate increases, while outlet RH decreases at steady state. The total vapor rate is defined as the sum of the membrane vapor transfer rate and inlet vapor rate, which represents total amount of vapor contained in the outlet of the humidifier. An important observation is that all the three response signals exhibit a NMP behavior as marked by circles in the figure. The NMP behavior has important implications on the overall control system design - we will come back to visit this important phenomenon later.

Figure 4 shows that when there is a step decrease in the inlet air temperature, the membrane vapor transfer rate decreases and the outlet RH increases slightly at steady state. More importantly, all the three response signals overshoot, which is quite unusual in thermodynamic systems because they are overdamped in nature.

Figure 5 shows that when there is a step increase in the inlet air $\mathrm{RH}$, the membrane vapor transfer rate decreases. This is due to the fact that the membrane vapor transfer rate, as described in Eq. (10), is a function of the RH difference across the membrane. When the inlet air RH increases, the RH gradient across the mem- 

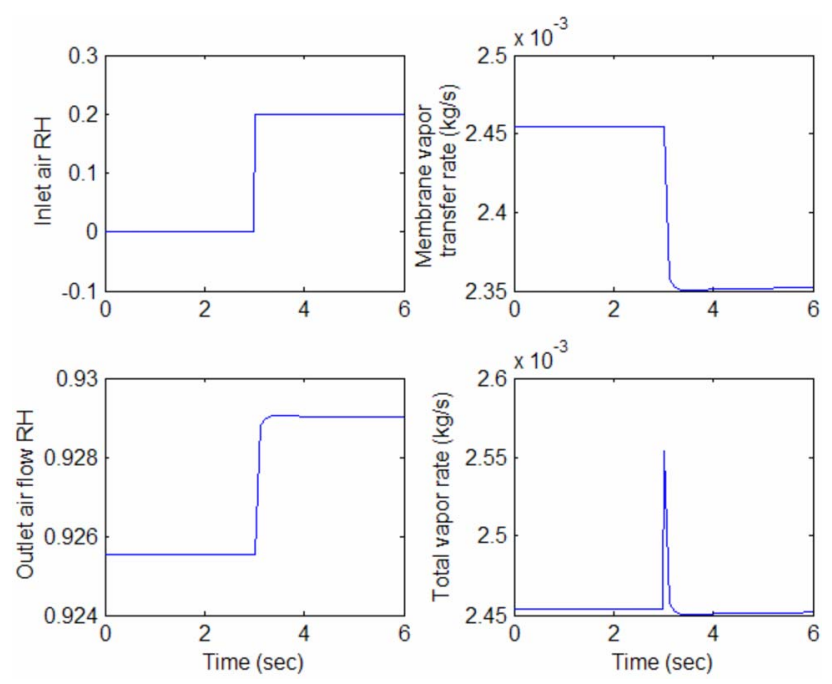

Fig. 5 System responses under a step increase of the inlet air $\mathrm{RH}$ (inlet air flow rate, $0.02785 \mathrm{~kg} / \mathrm{s}$; inlet air temperature, $303^{\circ} \mathrm{K}$; inlet water temperature, $353^{\circ} \mathrm{K}$ )

brane decreases; therefore, the membrane vapor transfer rate decreases. However, there is a little change of the total vapor rate because the inlet air RH increase compensates the membrane vapor transfer rate decrease. For the same reason, there is a little change of the outlet RH before and after the step disturbance.

In Figs. 3 and 4, there are no other sources of vapor going into the system; the total vapor rate goes into the system equals to the membrane vapor transfer rate. However, in Fig. 5, due to the inlet $\mathrm{RH}$ increases, the inlet vapor rate increases. The total vapor rate goes into the system equals the sum of the inlet vapor rate and the membrane vapor transfer rate.

3.2 Nonminimum-Phase Zero Analysis. Figure 3 shows that when the inlet air flow rate jumps the membrane vapor transfer rate, instead of immediately going toward its final steady-state value, initially goes in a direction opposite to its steady-state direction, thus exhibits an inverse response. This indicates that the system is a NMP system. The inlet air flow rate is determined by the fuel cell current, which could change suddenly during transient loads. In order to achieve the desired membrane vapor transfer rate, a control strategy manipulating the number of Type A humidifier units needs to be developed. However, the system exhibits NMP behavior, which could impose limit on closed-loop performance. NMP behaviors of certain type of dynamic systems can be affected by changing sensor and actuator locations $[7,8]$. The NMP behavior of the humidifier system, however, is intrinsic to the system behavior and is caused by the interaction between two independent factors. These two factors are the vapor mass stored in Control Volume 1, $m_{v, 1}$ and the temperature of Control Volume $1, T_{1, \text { out }}$. The membrane vapor transfer rate is a function of air outlet RH $\Phi_{1}$, which can be described as

$$
\Phi_{1}=\frac{P_{1, \text { out }}}{P_{\text {sat }}}
$$

Substitute $P_{\text {sat }}=f\left(T_{1, \text { out }}\right)$ and $P_{1, \text { out }}=m_{v, 1} R_{v} T_{1, \text { out }} / V_{\text {volume }}$, Eq. (21) becomes

$$
\Phi_{1}=\frac{m_{v, 1} R_{v} T_{1, \text { out }}}{f\left(T_{1, \text { out }}\right) V_{\text {volume }}}
$$

Define $C_{\Phi}=R_{v} / V_{\text {Volume }}$ and $g T=T_{1, \text { out }} / f\left(T_{1, \text { out }}\right)$, Eq. (22) becomes

$$
\Phi_{1}=C_{\Phi} m_{v, 1} g T
$$

The changing rate of the $\mathrm{RH}$ is then

$$
\dot{\Phi}_{1}=C_{\Phi}\left[\dot{m}_{v, 1} g T+m_{v, 1} g \dot{T}\right]
$$

Equation (24) shows that $\dot{\Phi}_{1}$ is a function of $\dot{m}_{v, 1}, g T, m_{v, 1}$ and $g \dot{T}$. The responses of these four variables under an inlet air flow rate step increase are plotted in Fig. 6, where $\dot{m}_{v, 1} g T$ is noted as "Element 1" and $m_{v, 1} g T$ is noted as "Element 2" (of Eq. (24)). Figure 6 shows that Element 1 reaches its peak later than Element 2 does.

The responses of RH and RH rate under a step increase in the inlet air flow are shown in Fig. 7. It can be seen that $\dot{\Phi}_{1}$ is positive before $t=3.1 \mathrm{~s}$ and negative afterwards. This causes $\Phi_{1}$, the outlet air $\mathrm{RH}$, to increase initially and then decrease. Our calculation shows that the area under the negative $\dot{\Phi}_{1}$ (from $t=3.1 \mathrm{~s}$ to infinity) is larger than that under the positive $\dot{\Phi}_{1}$. Therefore, the steady-state value of $\Phi_{1}$ is lower than the initial value, thus exhibiting a NMP behavior, as shown in Plot 4 of Fig. 7.

We have explained the NMP behavior of $\Phi_{1}$ and will establish the connection between this fact and the NMP response of $r_{v, \text { tr }}$ next. The membrane vapor transfer rate $r_{v \text {,tr }}$ is a function of $\Phi_{1}$, as explained in Eqs. (10)-(14). Since the water temperature changes slowly compared to other dynamic variables of the humidifier, $T_{w, \text { out }}$ is assumed to be constant. In addition, since the membrane is submerged in water, $T_{\text {mem }}=T_{w, \text { in }}+T_{w, \text { out }} / 2$. Therefore, the membrane coefficient of diffusion $D_{w}$ is assumed to be a constant, denoted as $D_{c}$. Because water flows through Control Volume 2, the water content on the water channel side $\lambda_{2}$ is assumed to be 14 [4]. Substituting $\lambda_{2}, D_{c}$, and Eq. (12), Eq. (10) becomes

$$
r_{v, \mathrm{tr}}=\frac{D_{c} G_{v} A \rho_{m, \mathrm{dry}}}{t_{m} G_{m, \mathrm{dry}}}\left(14-\lambda_{1}\right)
$$

where $D_{c} G_{v} A \rho_{m, \text { dry }} / t_{m} G_{m \text {,dry }}$ is constant and $r_{v, \text { tr }}$ depends on $-\lambda_{1}$ linearly. The nonlinear relationship between $\lambda_{1}$ and the RH $\Phi_{1}$ is shown in Fig. 8. Since $\lambda_{1}$ is a monotonic function of RH, if RH has a NMP response, $\lambda_{1}$ will also have a NMP response. Therefore, $r_{v, \mathrm{tr}}$, which depends linearly on $\lambda_{1}$, exhibits a NMP response.

The root locus plot of the linearized system shown in Fig. 9 confirms this finding. The system is linearized at state $x_{0}$ $=\left[\begin{array}{llll}0.0137 & 0.0007 & 352 & 353\end{array}\right]^{T}$, which corresponds to the operating point of $60 \mathrm{~A}$ for the fuel cell stack modeled in Ref. [5]. Figure 9 shows that there is a slow dynamic mode corresponding to the slow pole-zero pair. This slow dynamic mode arises from the water temperature dynamics. Assuming that the water temperature is constant, the state $T_{w, \text { out }}$ can be eliminated. The system order is then reduced from 4 to 3 , which simplifies the subsequent analysis. The transfer function from inlet air flow rate to membrane vapor transfer rate has the following form:

$$
H(s)=\frac{k\left(s+z_{1}\right)\left(s-z_{2}\right)}{\left(s+p_{1}\right)\left(s+p_{2}\right)\left(s+p_{3}\right)}
$$

where $p_{i}$ and $z_{i}$ are all positive.

Next, we will show that the selection of system parameters, such as the membrane thickness and channel cross-section dimension, could affect the NMP zero location. Assuming that all other system parameters are constant, the effect of membrane thickness on the NMP zero location is studied. The result is summarized in Table 2. It can be seen that the membrane thickness hardly affects the NMP zero locations.

Assuming that all other system parameters are constant, the effect of channel cross section dimension on the NMP zero location is investigated. The result is summarized in Table 3, which shows that smaller hydraulic diameters generate larger NMP zero values.

3.3 Experimental Validation. Since the NMP behavior is rare in mechanical systems, an experimental study is conducted to verify its existence. Figure 10 shows the schematic diagram of the 

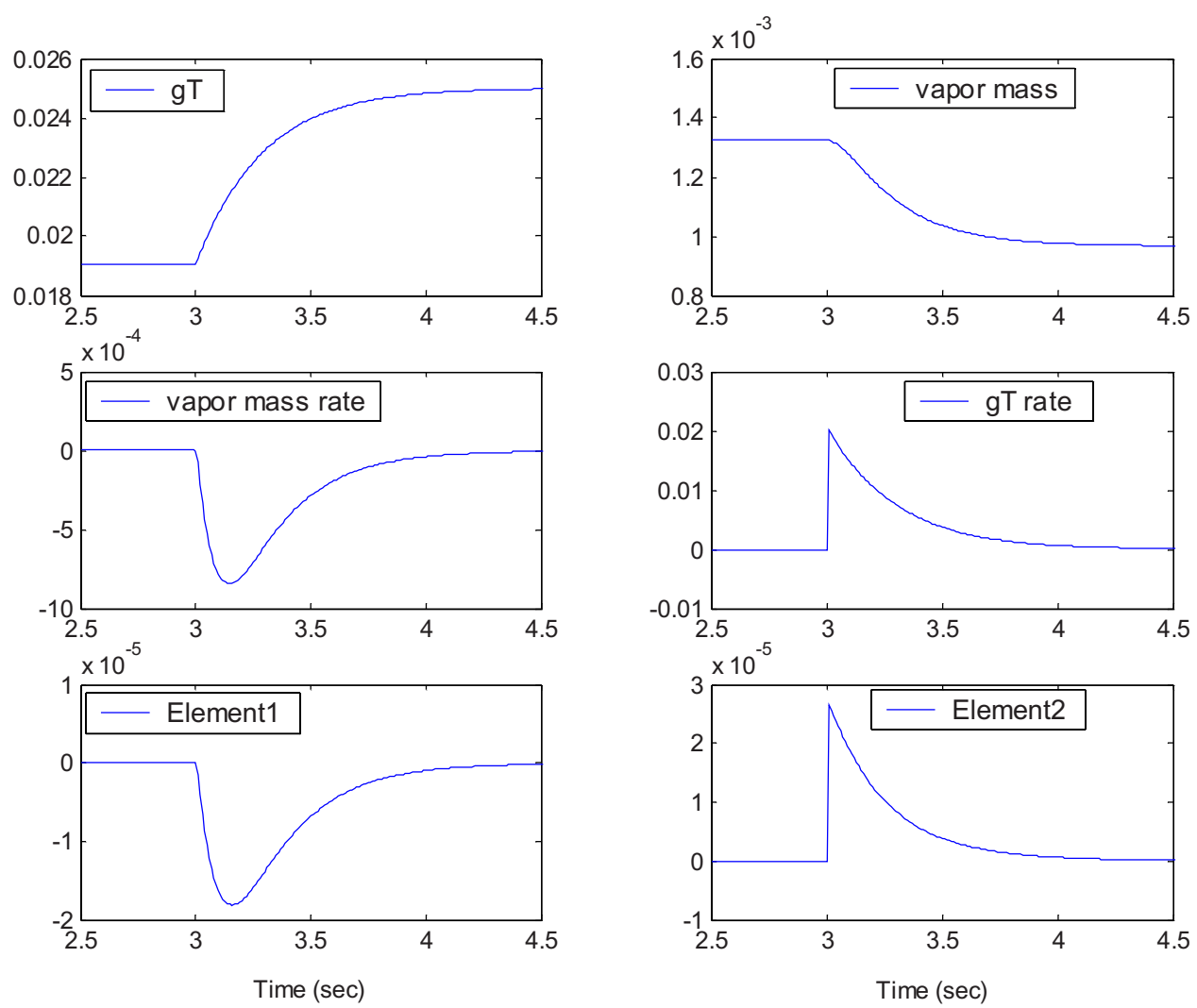

Fig. 6 System responses under an inlet air flow rate step increase

test setup, where a commercial humidifier (Perma Pure ${ }^{2}$ humidifier Model No. PH-60T-24SS) is used. This humidifier has 60 Nafion membrane tubes installed in a stainless steel shell. The gas (air) flows inside the membrane tubes, while the water flows between the membrane tubes and the stainless steel shell. The filtered compressed dry air is regulated by a flow controller and can be heated by an inline heater to desired temperature. The distilled water from the water tank was fed to the humidifier in a counterflow direction relative to the air flow. A heating pad wrapped around the outside of the stainless steel wall was used to control the water temperature. The water channel pressure was adjusted simply by changing the height of the water tank, $H$, as shown in Fig. 10

A computer and a data acquisition system were used to control the air flow rate and to record the sensors' readings. Since the membrane vapor transfer rate cannot be measured directly, the outlet air RH is recorded and used to calculate the membrane vapor transfer rate. Figure 11 shows experimental and simulation results of the outlet air $\mathrm{RH}$ under step changes of air flow rate from $50 \mathrm{slm}$ to $10 \mathrm{slm}$ and back to $50 \mathrm{slm}$. The model prediction catches the test result characters, such as the NMP behavior and the step changes. However, the simulation indicates stronger NMP behavior than the test data does. This might be caused by the slow RH sensor dynamics. The RH sensor is a VAISALA Humidity and Temperature Module 238 with a 15 s response time at $90 \%$ RH. Using $1 / 6 s+1$ to represent the $\mathrm{RH}$ sensor dynamics, the modified simulation result, showed as Mode $+R H$ in Fig. 11, agrees with the test data very well. Figure 11 confirms that humidifier outlet $\mathrm{RH}$ does exhibit NMP behavior. Since the membrane vapor transfer rate depends on $-\lambda_{1}$ linearly, as shown in Eq. (25), and $\lambda_{1}$ is a monotonic function of RH, as shown in Fig. 8, the membrane vapor transfer rate also has NMP behavior.

\footnotetext{
${ }^{2}$ Perma Pure is a registered trademark of Perma Pure Inc.
}

\section{Control Strategies}

From the previous sections, it has been confirmed that the membrane humidifier exhibits a NMP behavior. The NMP zero is not desirable if it exists in the input-to-output loop. This is due to the fact that the NMP zero imposes fundamental limits on the achievable feedback control performance, sensitivity, and robustness properties of a linear time invariant feedback system [9-11]. Typically, to affect system zeros, feedback compensator is not effective and a feed-forward part needs to be used [12-14]. For

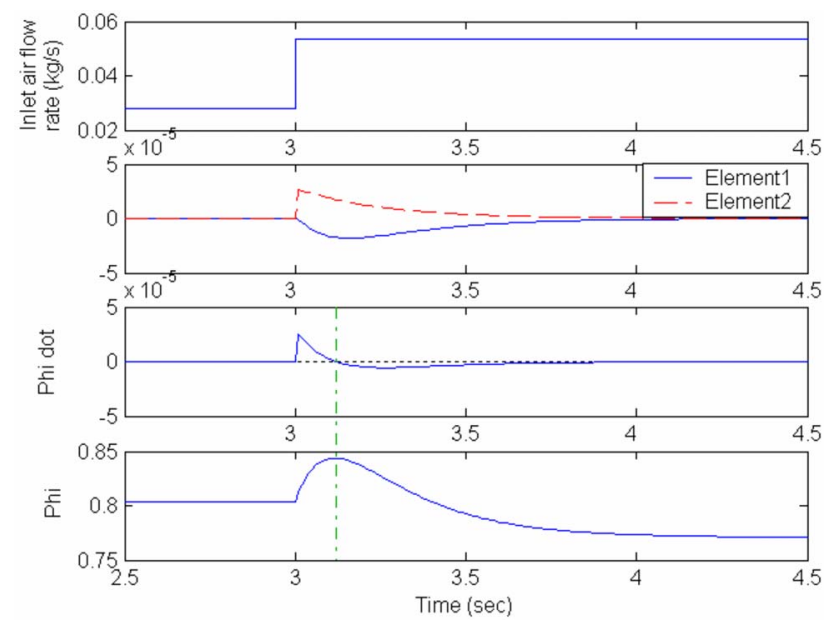

Fig. 7 Air outlet $\mathrm{RH}$ and $\mathrm{RH}$ rate responses under an inlet air flow rate step increase 


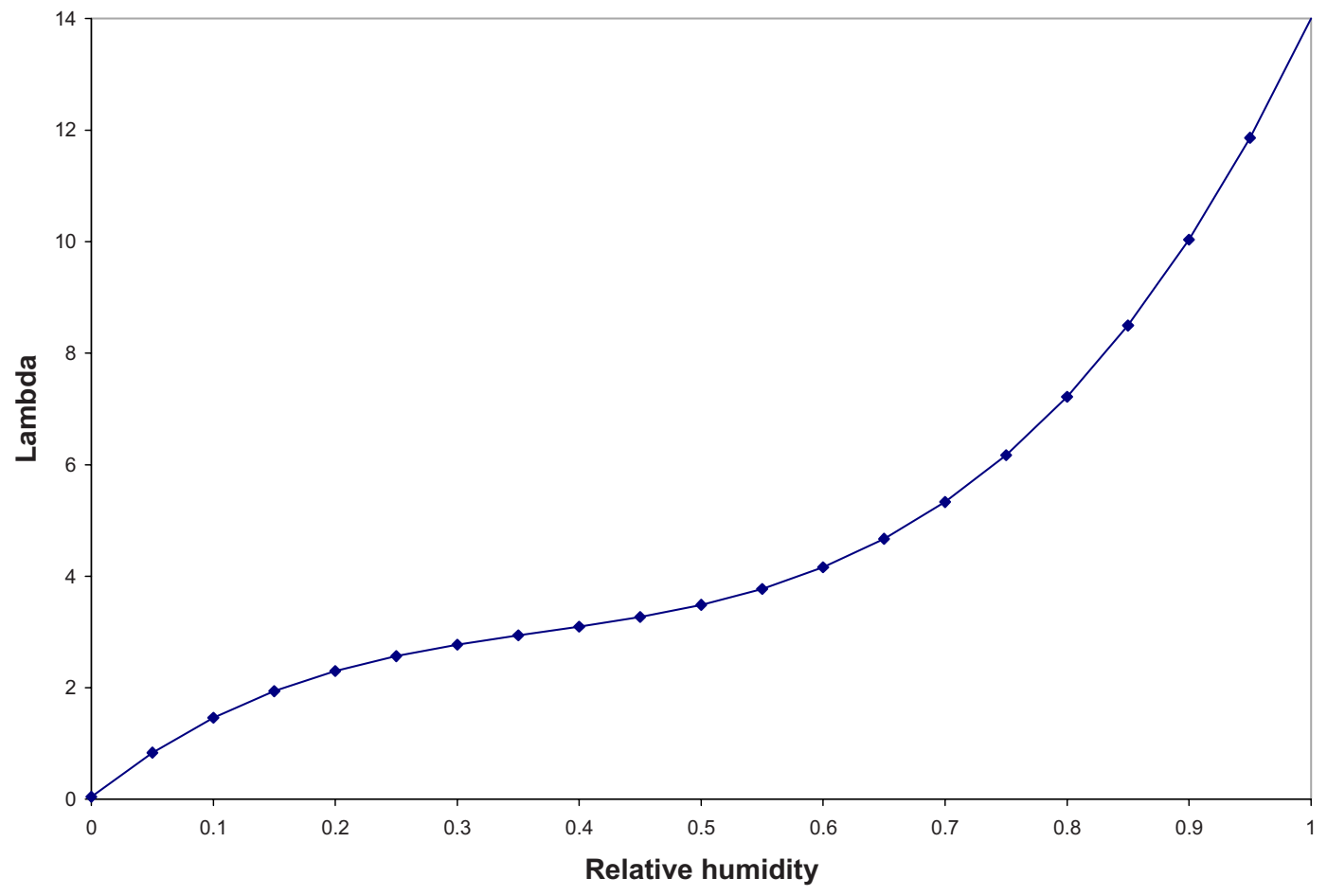

Fig. 8 Lambda versus gas $\mathrm{RH}$

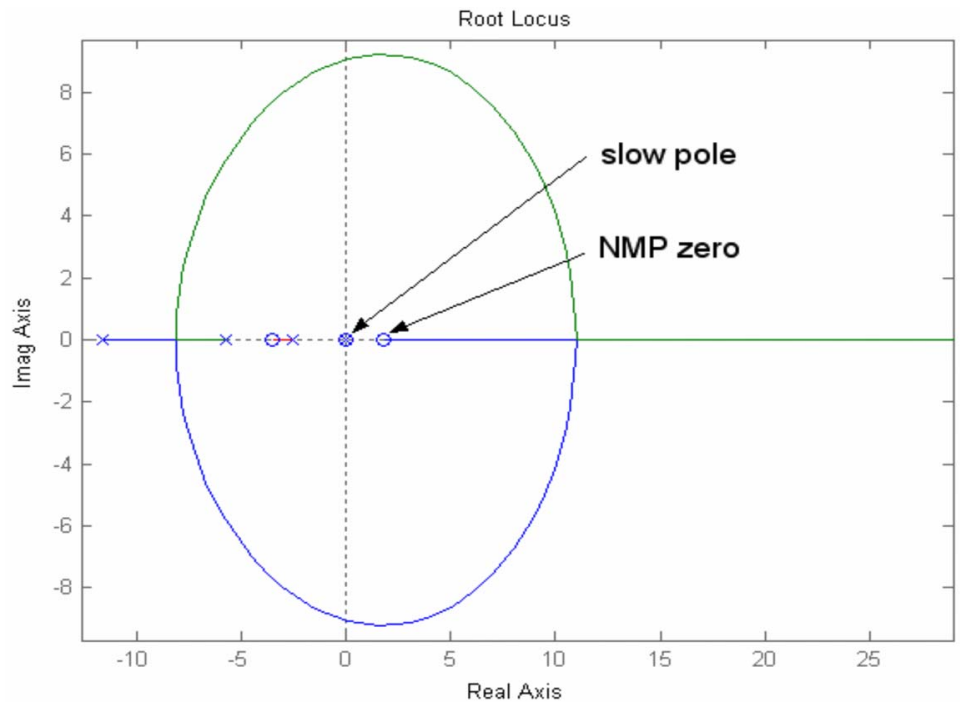

Fig. 9 Root locus of the four state system with the inlet air flow rate as the system disturbance

example, reference preview control is proposed in Ref. [9] to achieve accurate tracking without large transient errors or undershoots.

However, in the membrane humidifier system, the air flow rate is treated as a disturbance instead of an input to the system. Figure 12 shows the system control block diagram. The NMP zero exists in the disturbance-to-output loop instead of the input-to-output loop. Therefore, feedback control along can attenuate the NMP behavior. A feed-forward map is used to achieve the steady-state operation points. A feedback control is employed to reduce the undesired dynamic response. It should be pointed out that even though it is in the disturbance-to-output loop, the NMP zero could affect the feedback control design because the disturbance-tooutput loop is coupled with the input-to-output loop. The operation between the two loops is multiplication instead of addition.
Table 2 NMP zero value versus membrane thickness

\begin{tabular}{cc}
\hline \hline Membrane thickness $(\mathrm{cm})$ & NMP zero \\
\hline 0.005 & 21.08 \\
0.0125 & 20.71 \\
0.0175 & 20.64 \\
\hline \hline
\end{tabular}

Table 3 NMP zero value versus hydraulic diameter

\begin{tabular}{cc}
\hline \hline Hydraulic diameter $(\mathrm{m})$ & NMP zero \\
\hline 0.001 & 21.08 \\
0.002 & 8.953 \\
0.003 & 6.44 \\
0.004 & 5.3 \\
\hline \hline
\end{tabular}




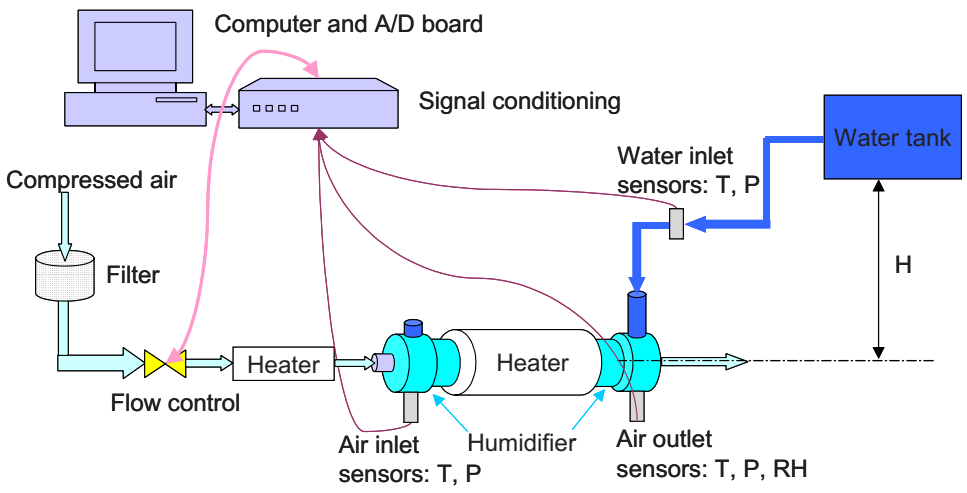

Fig. 10 Humidifier test setup: $T$, temperature; $\mathrm{P}$, pressure; $\mathrm{RH}$, relative humidity

The feedback controller gain could cause instability of the disturbance-to-output loop under closed-loop control. By trial and error, a proportional gain of 10,000 is selected. The control law is

$$
n=10000\left(\frac{\text { Desired vapor rate }}{1.107 \times 10^{-5}}+\text { Vapor rate error }\right)
$$

It is assumed that the total vapor rate in the humidifier outlet is calculated by using measurements from a mass flow sensor, a pressure transducer, a thermocouple, and a RH sensor, all placed at the humidifier outlet. The performance signal to be regulated is the total vapor rate of the outlet air. The target total vapor rate is computed from the fuel cell parameters and operation conditions
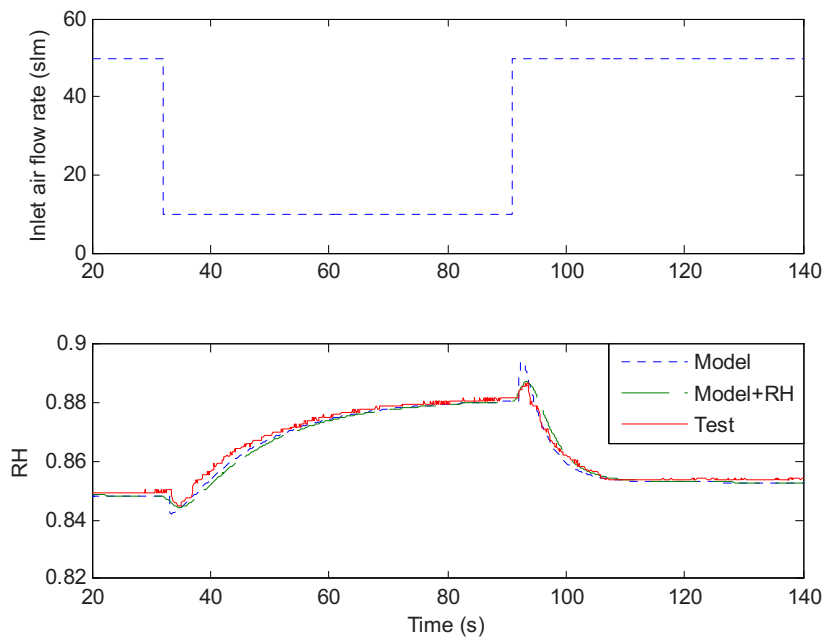

Fig. 11 Dynamic test result versus model prediction $\left(19^{\circ} \mathrm{C}\right.$ air inlet temperature; $12^{\circ} \mathrm{C}$ water temperature)

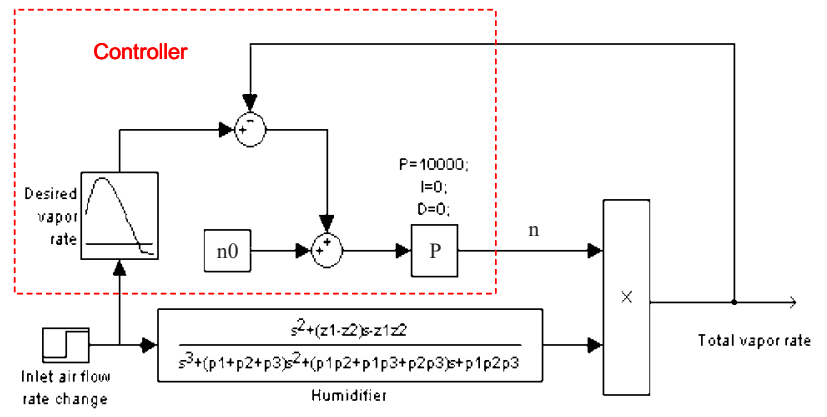

Fig. 12 System block diagram (see Fig. 13). By providing this vapor rate to the fuel cell, the fuel cell could maintain high $\mathrm{RH}$ without flooding the channel. Of course, this desired vapor rate signal is computed purely based on physics. Flooding/dehydration may still occur due to the nonuniform vapor distribution inside a stack because of improper stack channel geometry and gas-diffusion-layer designs. Here, we assume the fuel cell stack temperature is maintained at $80^{\circ} \mathrm{C}$. If the stack operates at other temperatures, new maps for the desired total vapor rate need to be developed.

The closed-loop simulation results are shown in Figs. 14-16, where the solid lines represent the open-loop system responses and the dotted lines represent the closed-loop system responses. In Fig. 14, we again simulate the condition where the inlet air flow rate steps up suddenly, a necessary response to an increased fuel cell load. By using the proposed control design, first, the output total vapor rate reaches the desired steady-state value; second, the NMP behavior of the total vapor rate has been attenuated. The closed-loop results under another two common operation perturbations are shown in Figs. 15 and 16. In both cases, the desired total vapor rate is assumed to remain unchanged (the fuel cell power remains constant), while the inlet air temperature suddenly changed (Fig. 15), or its RH suddenly changed (Fig. 16). The proposed feed-forward plus $\mathrm{P}$ control achieves accurate regulation in both cases.

It should be pointed out that the NMP zero in this study could affect the feedback controller gain. More detailed analysis will be

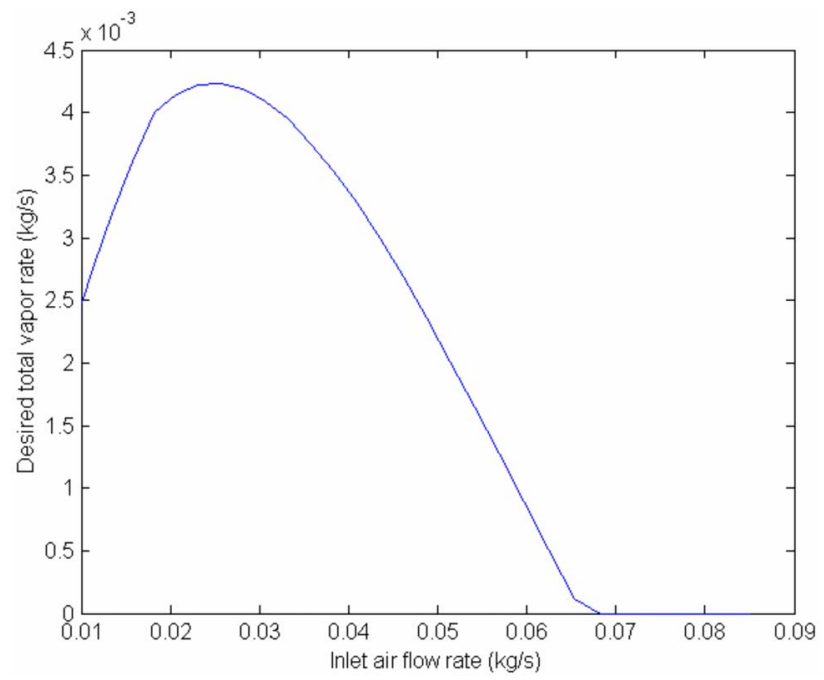

Fig. 13 Humidifier desired total vapor rate versus inlet air flow rate (based on Ford P2000 fuel cell prototype vehicle at $80^{\circ} \mathrm{C}$ ) 

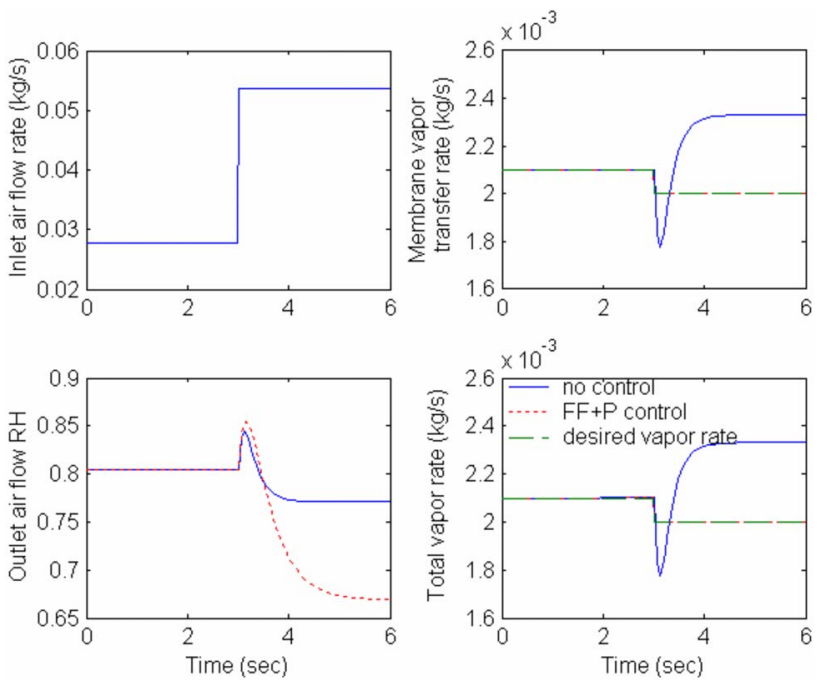

Fig. 14 System responses with and without control under an inlet air flow rate step increase (the dashed line and the dotted

conducted to investigate how the NMP zero limits the feedback control gain. Moreover, the controller performance and robustness will also be explored under system uncertainties, such as model parameter variations, model assumption accuracy, and unknown disturbances.

\section{Conclusions}

A membrane-based humidifier that uses water to humidify the dry gas is modeled and analyzed in this paper. The four-state lumped model describes the transient behavior of the humidification phenomenon and predicts that the system exhibits a NMP behavior. This NMP behavior is intrinsic to the system and caused by the lag of vapor mass rate in Control Volume 1. Even though it exists in the disturbance-to-output loop, the NMP zero could affect the feedback control gain due to the coupling effect between the input-to-output loop and the disturbance-to-output loop. A feedback controller is proposed to reject the system disturbance and a feed-forward map is used to compensate the air flow rate variation. The humidifier simulation results show that the above
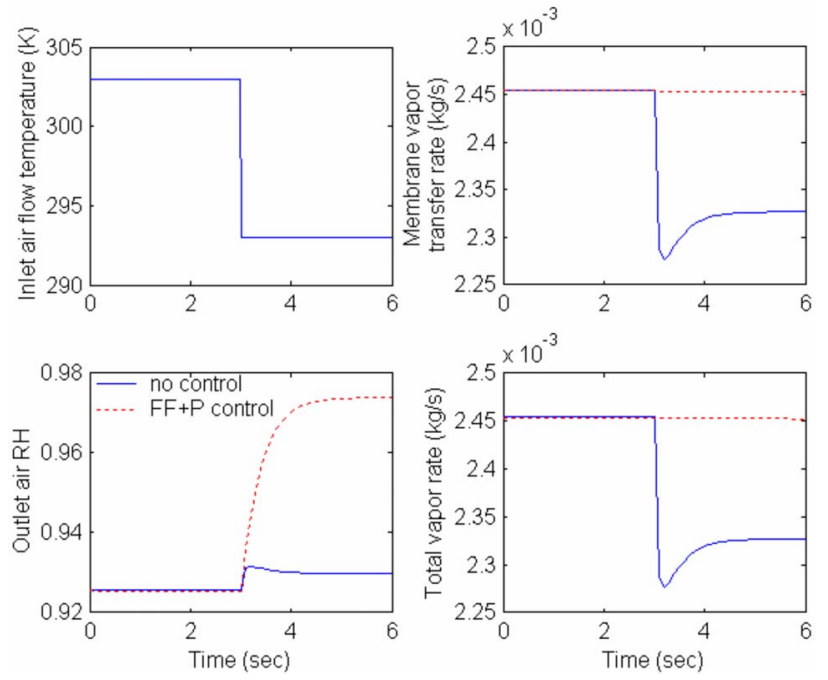

Fig. 15 System responses with and without control under an inlet temperature step decrease line are on top of each other in the right two plots)
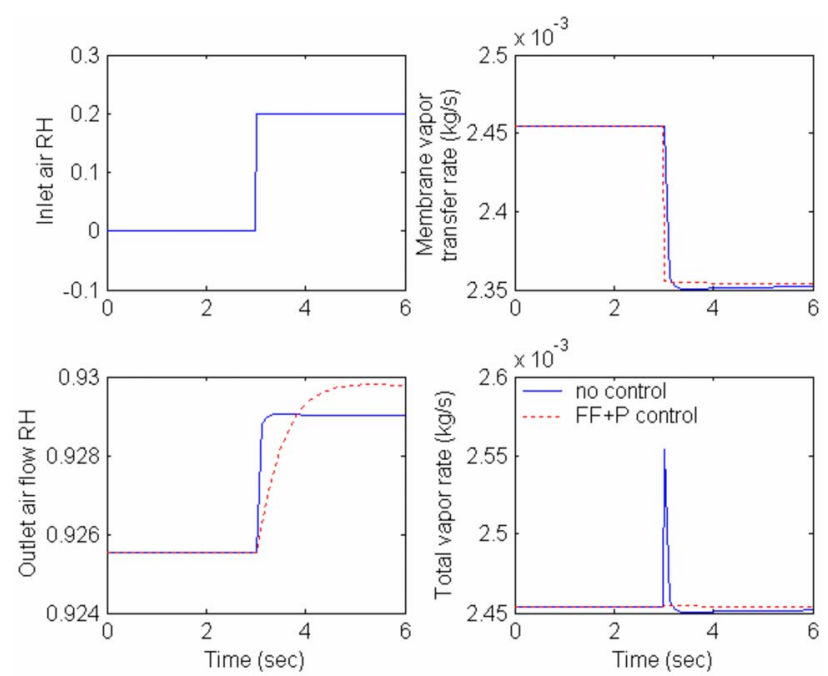

Fig. 16 System responses with and without control under an inlet $\mathrm{RH}$ step increase

control algorithms work well under uncertainties, such as the inlet air flow rate change and the inlet air temperature variation.

\section{Acknowledgment}

The authors wish to acknowledge the support from the University of Michigan Rackham Graduate School Fellowship.

\section{Nomenclature}

$$
\begin{aligned}
A & =\text { humidifier membrane area }\left(\mathrm{cm}^{2}\right) \\
C & =\text { water concentration }\left(\mathrm{mol} / \mathrm{cm}^{3}\right) \\
C_{p} & =\text { specific heat of constant pressure }\left(\mathrm{J} \mathrm{kg}^{-1} \mathrm{~K}^{-1}\right) \\
C_{r} & =\text { orifice restriction constant } \\
C_{v} & =\text { specific heat of constant volume }\left(\mathrm{J} \mathrm{kg}^{-1} \mathrm{~K}^{-1}\right) \\
D_{h} & =\text { channel hydraulic diameter }(\mathrm{m}) \\
D_{w} & =\text { membrane diffusion coefficient }\left(\mathrm{cm}^{2} / \mathrm{s}\right) \\
G_{g} & =\text { gas molecular mass }(\mathrm{kg} / \mathrm{mol}) \\
G_{m, \text { dry }} & =\text { membrane dry equivalent weight }(\mathrm{kg} / \mathrm{mol}) \\
G_{v} & =\text { water vapor molecular mass }(\mathrm{kg} / \mathrm{mol}) \\
h & =\text { enthalpy }(\mathrm{J}) \\
\bar{h} & =\text { heat transfer coefficient }\left(\mathrm{W} / \mathrm{m}^{2} \mathrm{~K}\right) \\
k & =\text { membrane thermal conductivity }(\mathrm{W} / \mathrm{m} \mathrm{K}) \\
m & =\text { mass-system state }(\mathrm{kg}) \\
N & =\text { total numbers of humidifier units } \\
n & =\text { No. of humidifier units with } \mathrm{A} \text { opened } \\
\mathrm{Nu}_{D} & =\text { Nusselt number } \\
P & =\text { pressure }(\text { Pa }) \\
Q r & =\text { heat transfer rate }(\mathrm{W}) \\
r & =\text { mass rate }(\mathrm{kg} / \mathrm{s}) \\
R & =\text { gas constant }(\mathrm{J} \mathrm{kg}-1 \mathrm{~K}-1) \\
T & =\text { temperature }(\mathrm{K}) \\
t_{m} & =\text { membrane thickness }(\mathrm{cm}) \\
u & =\text { internal energy }(\mathrm{J}) \text { or system input } \\
u r & =\text { rate of change of internal energy }(\mathrm{W}) \\
U & =\text { overall heat transfer coefficient }\left(\mathrm{W} / \mathrm{m}^{2} \mathrm{~K}\right) \\
V & =\text { volume }\left(\mathrm{m}^{3}\right) \\
x & =\text { system state vector } \\
y & =\text { system measurements } \\
\phi & =\text { relative humidity } \\
\lambda & =\text { water content } \\
\rho & =\text { density }\left(\mathrm{kg} / \mathrm{cm}{ }^{3}\right) \\
\omega & =\text { humidity ratio } \\
&
\end{aligned}
$$




\section{Subscripts}

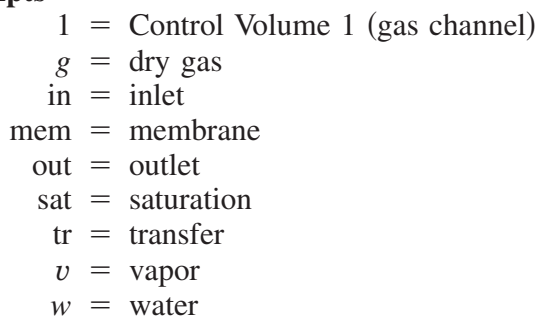

\section{References}

[1] Ciureanu, M., and Roberge, R., 2001, "Experimental Diagnostics and Modeling of Air Cathodes," J. Phys. Chem. 105, pp. 3531-3539.

[2] Chen, D., and Peng, H., 2005, "A Thermodynamic Model of Membrane Humidifiers for PEM Fuel Cell Humidification Control," ASME J. Dyn. Syst., Meas., Control 127, pp. 424-432.

[3] Nguyen, T. V., and White, R. E., 1993, "A Water and Heat ManagementMembrane Fuel Cells,” J. Electrochem. Soc. 140(8), pp. 2178-2186.

[4] Springer, T. E., Zawodzinski, T. A., and Gottesfeld, S., 1991, "Polymer Electrolyte Fuel Cell Model," J. Electrochem. Soc. 138(8), pp. 2334-2342.

5] Pukrushpan, J. T., Peng, H., and Stefanopoulou, A. G., 2002, "Simulation and Analysis of Transient Fuel Cell System Performance Based on a Dynamic
Reactant Flow Model," Proceedings of 2002 ASME International Mechanical Engineering Congress \& Exposition, New Orleans, LA.

[6] Incropera, F. P., and DeWitt, D. P., 1996, Introduction to Heat Transfer, 3rd ed., Wiley, New York.

[7] Miu, D. K., and Yang, B., 1994, "On Transfer Function Zeros of General Collocated Control Systems With Mechanical Flexibilities," ASME J. Dyn. Syst., Meas., Control 116, pp. 151-154.

[8] Suryanarayanan, S., and Tomizuka, M., 2001, "Lateral Control of Automated Vehicles: On Degraded Mode Control Problems," Proceedings of ASME International Mechanical Engineering Congress and Exposition, Vol. 2, pp. 10891100 .

[9] Middleton, R. H., Freudenberg, J. S., and McClamroch, N. H., 2001, "Sensitivity and Robustness Properties in the Preview Control of Linear NonMinimum Phase Plants," Proceedings of the American Control Conference, Arlington, VA, Jun. 25-27.

[10] Skogestad, S., and Postlethwaite, I., 1996, Multivariable Feedback ControlAnalysis and Design, Wiley, New York.

[11] Middleton, R. H., 1991, "Trade-Offs in Linear Control System Design," Automatica 27(2), pp. 281-292.

[12] Al-Hiddabi, S., Shen, J., and McClamroch, N. H., 1999, "Study of Flight Maneuvers for the PVTOL Aircraft Model," Proceedings of the American Control Conference, Vol. 4, pp. 2727-2731.

[13] Vipperman, J. S., and Burdisso, R. A., 1995, "Adaptive Feedforward Control of Non-Minimum Phase Structural Systems," J. Sound Vib., 183(3), pp. 369382.

[14] Fujimoto, H., and Yao, B., 2005, "Multirate Adaptive Robust Control for Discrete-Time Non-Minimum Phase Systems and Application to Linear Motors," IEEE/ASME Trans. Mechatron. 10(4), pp. 371-377. 